\title{
A POSSIBLE RADIO-ECHO METHOD OF LOCATING ENGLACIAL AND SUBGLACIAL WATERWAYS
}

by

Michael I. Kennett*

(H.H. Wills Physics Laboratory, University of Bristol, Bristol BS8 1TL, England, U.K.)

\section{ABSTRACT}

An array of radio echoes has been collected on Storglaciären in Sweden and used in an aperture-synthesis experiment. The digitized echoes were combined in a computer with suitable time shifts to focus on regions beneath the ice surface. The positions of six individual englacial cavities have been found, and the echoes from them isolated for interpretation. By performing the aperture synthesis with data sets from three different antenna configurations, information on the cavity shapes and orientations has been derived. At least five of the cavities are believed to be water-filled, and may be parts of an englacial drainage system. The technique could be applied to the problem of finding the principal water channel(s) in or under a glacier. Successful location would be of considerable importance in the planning of subglacial water intakes for hydro-electric power production.

\section{INTRODUCTION}

The position and distribution of subglacial and englacial water is important in many aspects of glaciology. For example, the dynamics of a glacier and the subglacial erosion processes are dependent on the distribution of water at the glacier bed. In addition, in Norway and France, hydro-electric power has been derived from water collected through subglacial intakes. These intakes must be situated under the major subglacial channel(s) to maximize water capture.

The Bondhusbreen hydro-electric power scheme in Norway was completed in 1978 and has been very successful (Hooke and others, 1985). In contrast, at Glacier d'Argentiere in France, subglacial water has bypassed the station intake since a major change in the glacier's drainage system in 1976. Construction is soon to begin on another scheme, at Engabreen in northern Norway.

An estimate of the position of the principal subglacial stream(s) can be obtained by mapping bed topography, through radio-echo sounding or by hot-water drilling. It should be noted, however, that the main water channel of a glacier does not necessarily lie in the deepest part of the bedrock. This paper describes a technique, known as aperture synthesis, for locating englacial or subglacial scatterers such as water channels from the glacier surface using a radio-echo sounder. Radio waves are scattered particularly effectively by water bodies, due to the high dielectric contrast between water and ice or rock. Radio-echo depth-sounding is usually accomplished with low-frequency (approx. $5 \mathrm{MHz}$ ) monopulse radar, but there are problems associated with this method because such radars have highly undirectional antennae with low gain,

*Present address: Glaciology Section, Norwegian Water Resources and Energy Administration, P.O. Box 5091, Majorstua, 0301 Oslo 3, Norway. thus it is difficult to identify the return from a particular scatterer and determine its position by the analysis of an individual radio echo. In the aperture synthesis, a set of radio echoes obtained within an area known as the aperture on the glacier surface are combined in a computer, so as to synthesize a high-gain directional radar. Aperture synthesis has many applications in other fields, notably in satellite remote sensing. It has also been applied to radio-echo data obtained on polar ice for detailed mapping of the glacier bed (Walford and Harper, 1979).

The experiments and results from Storglaciären in Sweden, where six englacial cavities were located, are explained in detail below. A discussion follows of the types of result that might be expected from an aperture synthesis when the target is an englacial or subglacial channel.

\section{APERTURE SYNTHESIS}

For the aperture synthesis, radio echoes $\psi_{i}(t)$ are recorded over a two-dimensional array of stations, $i$, on the glacier surface. The echoes are then transferred to a computer for manipulation. Using the computer, we choose a point $r^{\prime}=\left(r^{\prime}, \theta, \phi\right)$ in the ice, and for each station calculate the time delay $l_{i}$ of a return from a supposed scatterer at $r^{\prime}$. With the radar at the origin $\mathrm{O}$, and at $R$ (Fig. 1), the echo time delay would be respectively $t_{0}$ and $l_{i}$, where $t_{0}=2 r^{\prime} / v$ and $t_{i}=2 r_{i} / v, r_{i}$ is the radar-target

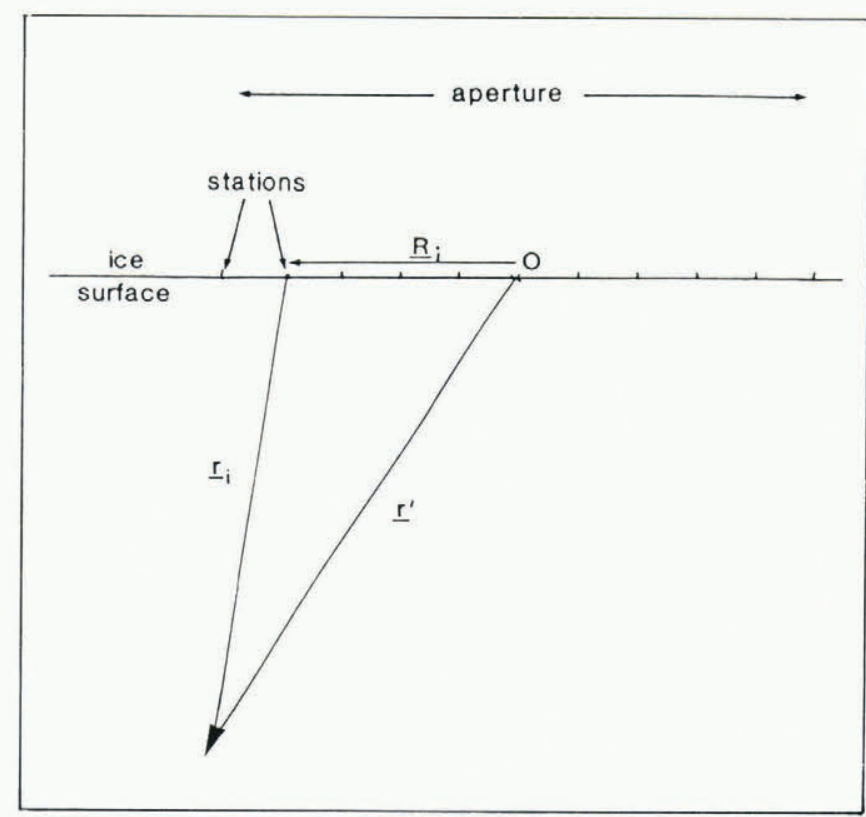

Fig. 1. Aperture-synthesis geometry: supposed target at $r^{\prime}$, radar at $R_{i}$ 
range with radar at $R_{i}$, and $v$ is a wave speed in ice of $168 \mathrm{~m} / \mu \mathrm{s}$. Each radio echo is then shifted in time by an amount, $\Delta t_{i}$, where

and

$$
\begin{aligned}
\Delta t_{i} & =t_{i}-t_{0} \\
\Delta t_{i} & =2\left(r_{i}-r^{\prime}\right) / v
\end{aligned}
$$

such that the returns from a scatterer at $r^{\prime}$ would occur simultaneously in the time-shifted radio echoes $\psi_{i}\left(t+\Delta t_{i}\right)$. Finally, the echoes are added together to give a resultant

$$
\Psi\left(r^{\prime}, t\right)=\sum_{i} \psi_{i}\left(t+\Delta t_{i}\right) .
$$

If there is a scatterer at $r^{\prime}$, all returns from it would add coherently in $\Psi\left(r^{\prime}, t\right)$, producing a large signal in the resultant. However, returns from scatterers at $r \neq r^{\prime}$ add incoherently and therefore the return from the scatterer at $r^{\prime}$ is enhanced relative to the echoes from other scatterers. A necessary criterion for the returns from such a focused scatterer to add coherently is that the shape of the return does not change significantly as the radar is moved around inside the aperture.

Scatterers are thus located by searching for points $r$ where the aperture synthesis resultant $\psi(r, t)$ becomes large. In practice, rather than examining $\Psi(r, t)$, we define a total resultant energy

$$
\mathrm{W}(\boldsymbol{r})=\int \mathrm{d} t \psi^{2}(\boldsymbol{r}, t)
$$

and search for significant maxima in $W(\boldsymbol{r})$. These maxima are of finite size in $r$ due to diffraction, their size being determined by the ratio of radar wavelength to aperture dimension, in a manner analagous with other imaging systems. A small aperture and/or large wavelength produces a wide diffraction pattern and thus poor resolution. Having found a maximum in $W(\boldsymbol{r})$, the resultant, $\Psi(\boldsymbol{r}, t)$, is then examined to obtain target parameters such as range and scattering strength.

\section{POLARIZATION}

Additional target parameters such as orientation, shape and composition, can be derived by recording echo polarization, that is from the vector nature of the scattered electromagnetic wave. Because of this, radio echoes were collected on Storglaciären in various antenna orientations.

Typically, the wave scattered back from a target to the receiving antenna has a polarization state which is different from that of the transmitted wave. The polarization -scattering properties of a target are described by a symmetrical scattering matrix $[S]$ of $2 \times 2$ elements:

$$
[S]=\left(\begin{array}{ll}
s_{11} & s_{12} \\
s_{21} & s_{22}
\end{array}\right)
$$

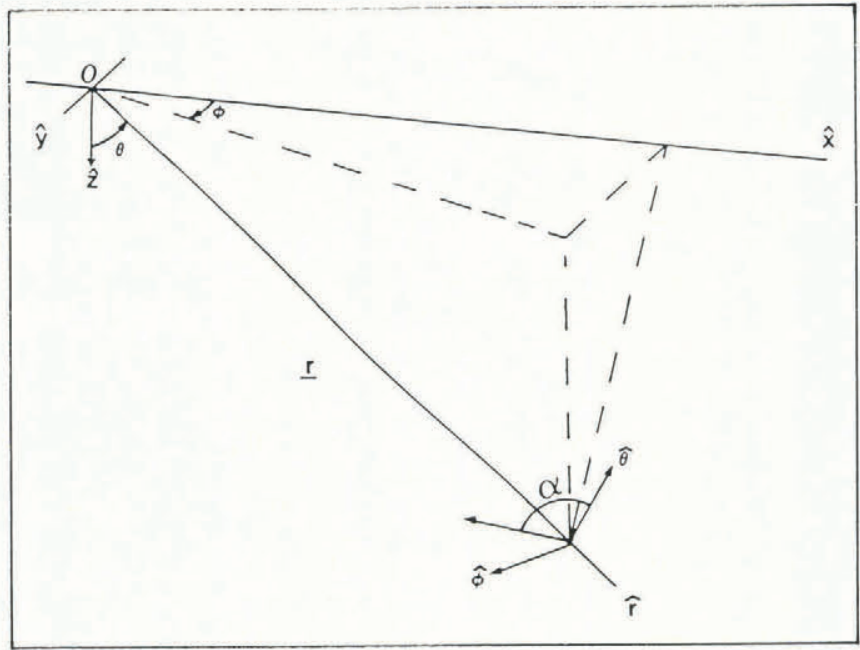

Fig. 2. Axes $\hat{\theta}, \hat{\phi}, \hat{r}$ at $r$. $\alpha$ is an orientation angle in the $(\hat{\theta}, \hat{\phi})$ plane.

(Huynen, 1978). This matrix relates the amplitude, phase, and polarization of the incident and back-scattered waves $E_{\mathrm{I}}$ and $E_{\mathrm{R}}$, according to the equation

$$
E_{\mathrm{R}}=\frac{1}{r}[S] E_{\mathrm{I}}
$$

where $r$ is the radar-target range. The scattering matrix is important in target identification (Boerner, 1983). It has two eigenvectors, corresponding to those two perpendicular polarization states which are not depolarized on scattering; that is, the returned wave, $E_{\mathrm{R}}$, has the same polarization state as the incident wave, $\boldsymbol{E}_{\mathrm{I}}$. Determination of the orientation of these cross-polarization nulls is useful in interpretation of target orientation. The eigenvalues of $[S]$ give target-scattering strength, and are therefore indicative of target dimensions. $[S]$ can be found from the received signal measured with three different configurations of the transmitter and receiver antennae, and is defined with respect to $\hat{\theta}$ and $\hat{\phi}$ axes (Fig. 2).

\section{EXPERIMENTAL DETAILS}

The radio-echo data were collected on Storglaciären in Sweden. The experimental site consisted of an array of $10 \times 10$ stations with $5 \mathrm{~m}$ spacing, near the glacier's centre line and approximately $500 \mathrm{~m}$ down-glacier from the equilibrium line. Echoes were obtained using a $5.8 \mathrm{MHz}$ monopulse radar of conventional design (similar to that of Sverrisson and others (1980)). This low frequency was chosen so that echoes from deep targets would not be too severely attenuated (Watts and England, 1976). The trans-
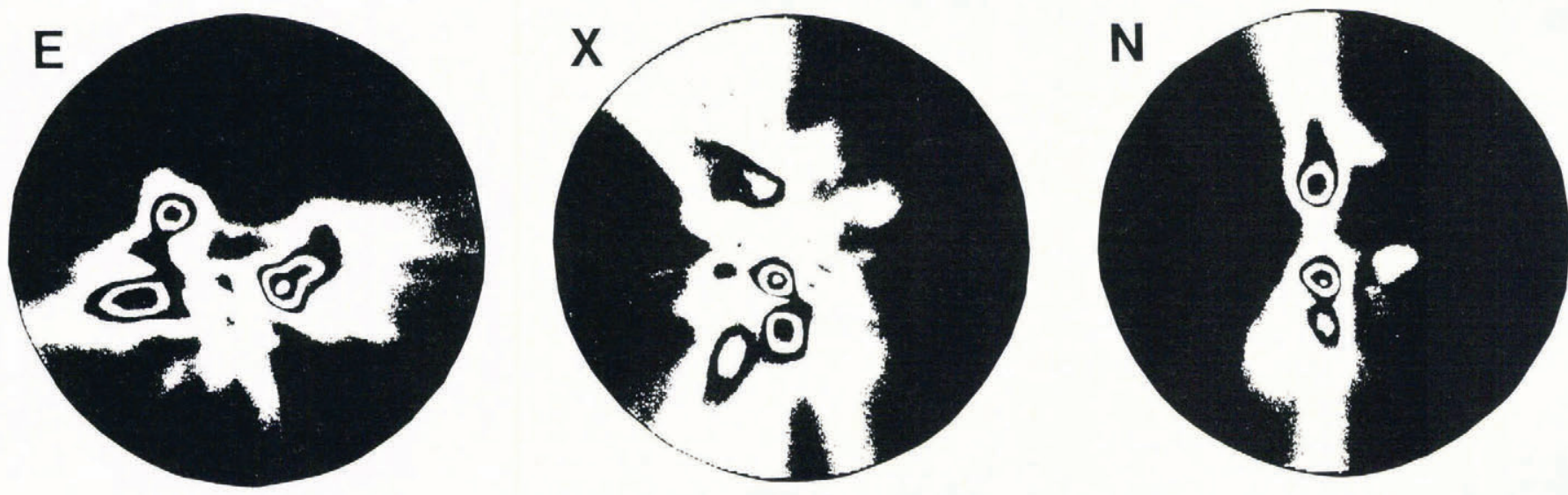

Fig. 3. Stereographic projections of resultant energies $W(r), r=100 \mathrm{~m}$, in $\mathrm{E}, \mathrm{X}$, and $\mathrm{N}$ antenna configurations. 


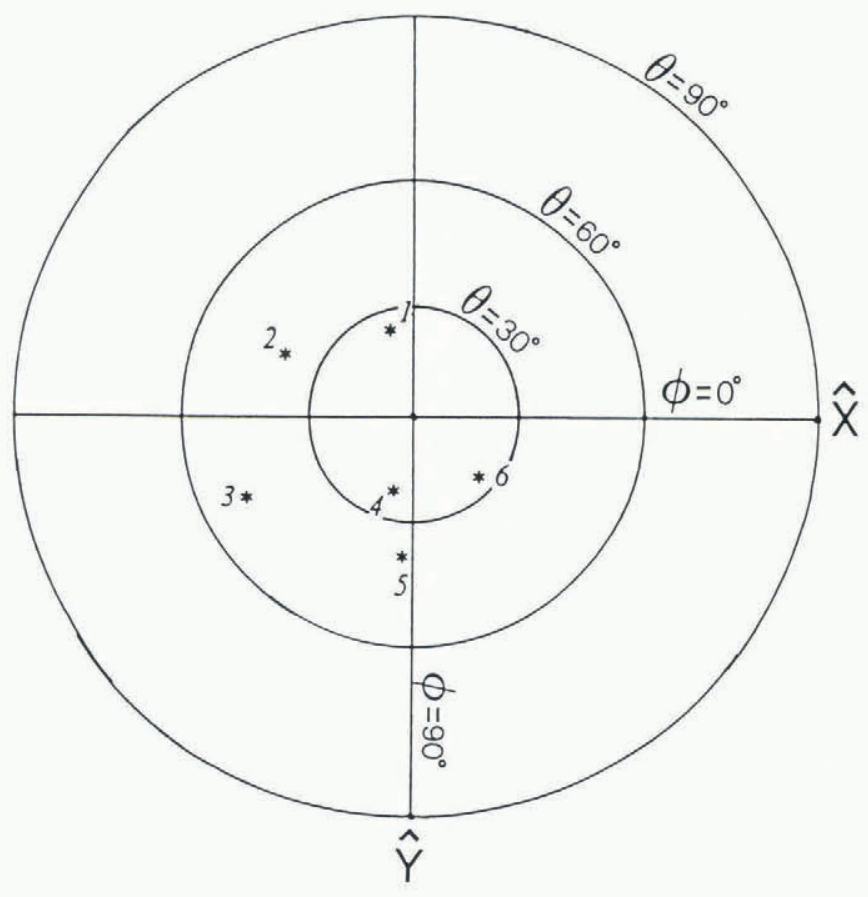

Fig. 4. Directions to scatterers $\mathrm{Tl}$ to $\mathrm{T} 6$, shown as a stereographic projection. $\theta, \phi, \hat{x}$, and $\hat{y}$ are as defined in Figure 2.

mitter and receiver were linked by an optic cable, enabling accurate and reliable triggering of the receiver regardless of antenna orientation. The two antennae were centre-fed, resistively loaded dipoles, each $2 \times 6.5 \mathrm{~m}$ long, supported on fibre glass roach poles. With the transmitter positioned $9 \mathrm{~m}$ south of a given station and the receiver $9 \mathrm{~m}$ north, three echoes were displayed and photographed in turn: $\psi_{E}(t)$ for both antenna axes pointing eastwards, that is parallel to $y$; $\psi_{\mathrm{N}}(t)$ for both pointing northwards; and $\psi_{\mathrm{X}}(t)$ for transmitter antenna northwards, receiver eastwards (Fig. 2). Three echoes were thus collected at each of the 100 stations and later digitized and transferred to a computer.

\section{RESULTS}

Each sub-set of 100 radio echoes with a given antenna configuration was used in a separate aperture synthesis. Resultant energies, $W(r)$, are shown in Figure 3. The images are stereographic projections (Fig. 4; Nye, 1985) of $W(\boldsymbol{r})$, calculated over a hemisphere of radius $100 \mathrm{~m}$ centred on the array. A few bright spots can be seen on the images in regions where $W(\boldsymbol{r})$ is large. In some directions, for example at $(\theta, \phi)=\left(20^{\circ}, 105^{\circ}\right)$, we see a spot in more than one of the syntheses. Having located regions of large resultant energy, $W(\boldsymbol{r})$, the associated resultants were examined. Figure 5 shows $\Psi_{\mathrm{E}}(t), \Psi_{\mathrm{X}}(t)$, and $\Psi_{\mathrm{N}}(t)$, corresponding to the spots labelled $\mathrm{Tl}_{1}$ and $\mathrm{T} 6$ in Figure 4, where the subscript E, X, or $\mathbf{N}$ denotes the antenna configuration of the radio echoes used in the synthesis. A single, large transient can be seen in each resultant, at $t \approx 0.7 \mu \mathrm{s}$ for $\mathrm{Tl}$, and at $t \approx 0.75 \mu \mathrm{s}$ for T6.

The six brightest spots from Figure $3, \mathrm{~T} 1$ to $\mathrm{T} 6$ (as indicated in Figure 4), have been selected for closer examination. The transients for targets $\mathrm{T} 2$ to $\mathrm{T} 5$ are similar in form to those of $\mathrm{Tl}$ but vary in amplitude and time delay. The three transients corresponding to each of the six spots occur at very similar time delays, even though each was generated with an independent set of 100 echoes. This provides strong evidence that they are due to real englacial scatterers (cavities) rather than to the fortuitous combination of unrelated echoes. The widths of the maxima in Figure 3 give no indication of target dimensions, but are merely a consequence of diffraction. The small ratio of aperture size to wavelength, $45 \mathrm{~m}: 30 \mathrm{~m}$, causes a diffraction pattern which is wide in $\hat{\theta}$ and $\hat{\phi}$, and highly extended in the $r$ direction. Target position coordinates, $\theta$ and $\phi$, are obtained
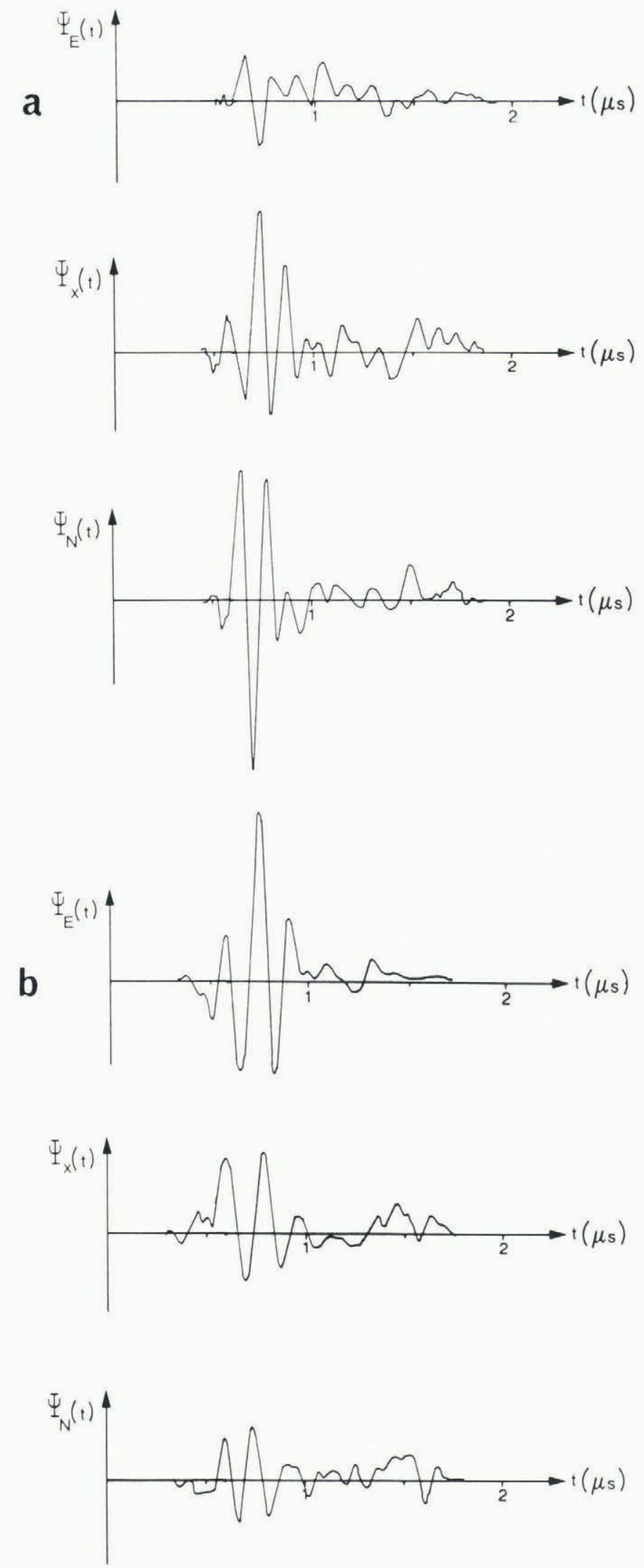

Fig. 5. Aperture-synthesis resultants at $(r, \theta, \phi)=($ a) $(100 \mathrm{~m}$, $\left.25^{\circ}, 255^{\circ}\right)$ and (b) $\left(100 \mathrm{~m}, 25^{\circ}, 40^{\circ}\right)$.

from Figure 3, and range, $r$, from transient time delay in the resultants. Transient amplitudes, $\Psi_{E}, \Psi_{X}$, and $\Psi_{N}$, and target position, $r$, have then been used to calculate a scattering matrix for each target. This has been achieved by making the approximation that the three transients corresponding to each target are in phase or antiphase with one another. This is reasonable for T1 to T5 but gives a poor approximation for T6 (Fig. 5). Table I shows the 
TABLE I. POSITION AND SCATTERING MATRICES OF TARGETS T1 TO T6. EIGENVECTOR ORIENTATIONS ARE EXPRESSED WITH RESPECT TO $\hat{\theta}$, AS $\alpha$ OF FIGURE 2

\begin{tabular}{|c|c|c|c|c|c|}
\hline Target & Position & Depth & {$[S]$} & $\begin{array}{l}\text { Eigen- } \\
\text { values }\end{array}$ & $\begin{array}{r}\text { Eigenvector } \\
\text { orientations }\end{array}$ \\
\hline & $\begin{array}{l}r \\
\theta \\
\phi\end{array}$ & & $\begin{array}{l}\mathrm{s}_{11} \\
\mathrm{~s}_{12} \\
\mathrm{~s}_{22}\end{array}\left(=\mathrm{S}_{21}\right)$ & $\begin{array}{l}\gamma_{1} \\
\gamma_{2}\end{array}$ & $\begin{array}{l}\alpha_{1} \\
\alpha_{2}\end{array}$ \\
\hline & & (m) & (m) & (m) & \\
\hline T1 & $\begin{array}{r}59 \mathrm{~m} \\
25^{\circ} \\
255^{\circ}\end{array}$ & 53 & $\begin{array}{l}0.010 \\
0.003 \\
0.195\end{array}$ & $\begin{array}{l}0.195 \\
0.010\end{array}$ & $\begin{array}{r}89^{\circ} \\
179^{\circ}\end{array}$ \\
\hline T2 & $\begin{array}{r}77 \mathrm{~m} \\
40^{\circ} \\
205^{\circ}\end{array}$ & 59 & $\begin{array}{r}0.016 \\
-0.007 \\
0.158\end{array}$ & $\begin{array}{l}0.158 \\
0.015\end{array}$ & $93^{\circ}$ \\
\hline $\mathrm{T} 3$ & $\begin{array}{l}81 \mathrm{~m} \\
50^{\circ} \\
155^{\circ}\end{array}$ & 52 & $\begin{array}{r}0.038 \\
-0.010 \\
0.146\end{array}$ & $\begin{array}{l}0.147 \\
0.038\end{array}$ & $95^{\circ}$ \\
\hline $\mathrm{T} 4$ & $\begin{array}{l}75 \mathrm{~m} \\
20^{\circ} \\
105^{\circ}\end{array}$ & 70 & $\begin{array}{l}0.041 \\
0.025 \\
0.278\end{array}$ & $\begin{array}{l}0.281 \\
0.039\end{array}$ & $84^{\circ}$ \\
\hline T5 & $\begin{array}{c}100 \mathrm{~m} \\
40^{\circ} \\
95^{\circ}\end{array}$ & 77 & $\begin{array}{r}0.104 \\
-0.185 \\
0.326\end{array}$ & $\begin{array}{l}0.429 \\
0.000\end{array}$ & $\begin{array}{r}119^{\circ} \\
29^{\circ}\end{array}$ \\
\hline T6 & $\begin{array}{l}72 \mathrm{~m} \\
25^{\circ} \\
40^{\circ}\end{array}$ & 65 & $\begin{array}{l}0.171 \\
0.031 \\
0.083\end{array}$ & $\begin{array}{l}0.180 \\
0.074\end{array}$ & $\begin{array}{r}18^{\circ} \\
108^{\circ}\end{array}$ \\
\hline
\end{tabular}

calculated scattering matrices, together with their eigenvalues. Most of the targets have a large ratio of eigenvalues, $\gamma_{1}: \gamma_{2}$, and are thus strongly depolarizing; that is the polarization state of the scattered wave can differ substantially from that of the incident wave.

Frequency analysis of the transients, and examination of their forms, shows that the scattering is frequencydependent, and suggests that targets T1 to T5 are Rayleighlike (Kennett, unpublished); that is to say that the target dimension is much smaller than the radar wavelength and scattered wave amplitude varies with the square of frequency. In this case, these targets are too strongly depolarizing to be accounted for by air-filled cavities because, due to the relatively small dielectric contrast between ice and air, Rayleigh-like air-filled cavities are only weakly depolarizing. Boulders or debris can be ruled out as possible scattering sources, since Storglaciären is almost completely free of surface rock debris in the area where these scatterers would melt out. We conclude therefore that cavities T1 to T5 are probably water-filled,

TABLE II. RAYLEIGH-LIKE SPHEROID SOLUTIONS FOR TARGETS TI TO T6. SPHEROID SEMI-AXES $a, b, c, a \neq b=c$, WITH $a$-AXIS LYING IN THE $(\hat{\theta}, \hat{\phi})$ PLANE. $\alpha_{\dot{a}}$ IS ORIENTATION OF $a$-AXIS WITH RESPECT TO $\hat{\theta}$, AS $\alpha$ OF FIGURE 2

\begin{tabular}{|c|c|c|c|c|c|}
\hline Target & Spheroid type & $\alpha_{a}$ & $\begin{array}{l}a \\
(\mathrm{~m})\end{array}$ & $\begin{array}{c}b(=c) \\
(\mathrm{m})\end{array}$ & $\begin{array}{l}\text { Volume } \\
\left(\mathrm{m}^{3}\right)\end{array}$ \\
\hline $\mathrm{T} 1$ & oblate; water-filled & $179^{\circ}$ & 0.04 & 4.0 & 2.5 \\
\hline $\mathrm{T} 2$ & $\begin{array}{l}\text { oblate; water-filled } \\
\text { prolate; water-filled }\end{array}$ & $93^{\circ}$ & $\begin{array}{l}0.1 \\
6.7\end{array}$ & $\begin{array}{l}2.6 \\
0.3\end{array}$ & $\begin{array}{l}3.5 \\
2.0\end{array}$ \\
\hline $\mathrm{T} 3$ & $\begin{array}{l}\text { oblate; water-filled } \\
\text { prolate; water-filled }\end{array}$ & $95^{\circ}$ & $\begin{array}{l}0.5 \\
2.6\end{array}$ & $\begin{array}{l}2.0 \\
0.7\end{array}$ & $\begin{array}{l}7.5 \\
5.0\end{array}$ \\
\hline T4 & $\begin{array}{l}\text { oblate; water-filled } \\
\text { prolate; water-filled }\end{array}$ & $\begin{array}{r}174^{\circ} \\
84^{\circ}\end{array}$ & $\begin{array}{l}0.3 \\
4.4\end{array}$ & $\begin{array}{l}2.7 \\
0.5\end{array}$ & $\begin{array}{l}8.5 \\
5.5\end{array}$ \\
\hline T5* & $\begin{array}{l}\text { oblate; water-filled } \\
\text { prolate; water-filled }\end{array}$ & $\begin{array}{r}29^{\circ} \\
119^{\circ}\end{array}$ & $\begin{array}{l}0.0 \\
-\end{array}$ & $0 . \overline{0}$ & $\begin{array}{l}4.5 \\
4.5\end{array}$ \\
\hline T6 & $\begin{array}{l}\text { oblate; water-filled } \\
\text { prolate; water-filled } \\
\text { oblate; air-filled }\end{array}$ & $\begin{array}{r}108^{\circ} \\
18^{\circ} \\
18^{\circ}\end{array}$ & $\begin{array}{l}0.8 \\
2.3 \\
0.3\end{array}$ & $\begin{array}{l}1.9 \\
1.0 \\
4.5\end{array}$ & $\begin{array}{r}12 \\
9 \\
25\end{array}$ \\
\hline
\end{tabular}

* No spheroid fits $[S]$ exactly. Nearest solutions are water-filled oblate spheroid, $a / b \rightarrow 0$; and water-filled prolate spheroid, $a / b \rightarrow \infty$. 
but that T6 could be either water-filled or air-filled.

Kennett (unpublished) has modelled these six targets as spheroidal cavities of air or water, and has calculated both values of the semi-axes, $a, b, c$ (where $a \neq b=c$ ), and orientation which fit the scattering matrices of Table I. These solutions are shown in Table II. This model may have some physical significance, since a section of a water channel can be represented approximately as a prolate spheroid, $a \gg b=c$, and a crevasse as an oblate spheroid, $a \ll b=c$. However, there are many other cavity shapes, sizes, and orientations which could also produce each of the calculated scattering matrices.

\section{LOCATION OF CHANNELS}

Having demonstrated that englacial cavities can be located through aperture synthesis, we now turn to the problem of locating englacial and subglacial channels. Channels are likely to be complex and possibly meandering features of variable width. The scattering from them would thus be very complicated, but we might expect stronger returns from regions where, for example, a channel became wider or was orientated parallel with the radar antennae. An aperture synthesis would then enhance the signal from these regions.

The problem of locating subglacial channels is further complicated by the presence of the glacier bed, which is likely to be a stronger scatterer than a channel. However, unless such a channel lay near the reflecting point on the bed, the bed echo and return from the channel would be separated in time and thus distinguishable in an aperture synthesis.

\section{CONCLUSION}

Aperture synthesis represents a new application of ice radar. Although it has been used before to obtain the detailed form of a glacier bed (Walford and Harper, 1981), it has not previously been applied to the problem of locating and analysing englacial or subglacial water bodies. The technique is a powerful method of identifying scatterers which are not visible in individual radio echoes. Its principal drawback is the time involved in digitizing the radar data. However, the use of a data-acquisition system instead of film would aid analysis considerably.

It is not possible to draw major conclusions about the hydrology of Storglaciären from the analysis of six englacial cavities presented here. Most of them are considered to be fossils of water-filled crevasses, or sections of water channels which may or may not have been part of the then active englacial water system. Aperture synthesis could be used very effectively to locate major englacial waterways of interest, and possibly also the principal subglacial channels. Large channels are likely to be stronger scatterers than isolated cavities, and should thus be easier to detect. Thick ice and the presence of the glacier bed might however make a subglacial channel more difficult to locate than englacial water bodies. By repeating the aperture-synthesis experiment with data sets obtained at different times, it may be possible to examine the stability of glacial drainage systems.

\section{ACKNOWLEDGEMENTS}

I should like to thank M.E.R. Walford for considerable guidance and encouragement throughout the work, and R.L. Hooke, P. Holmlund, and the rest of the Tarfala research team for help and support in the field. This work was sponsored by the U.K. Natural Environmental Research Council.

\section{REFERENCES}

Boerner, W.M., ed. 1983. Proceedings of the NATO Advanced Research Workshop on inverse methods in electromagnetic imaging, Bad Windsheim, West Germany, September 18-24, 1983. NATO ASI, 143C.

Hooke, R. LeB., B. Wold, and J.O. Hagen. 1985. Subglacial hydrology and sediment transport at Bondhusbreen, southwest Norway. Geol. Soc. Am. Bull., 96(3), 388-397.

Huynen, J.R. 1978. Phenomenological theory of radar targets. In Uslenghi, P.L.E., ed. Electromegnetic scattering. New York, Academic Press, 653-712.

Kennett, M.I. Unpublished. An analysis of the scattering of radio waves within a temperate glacier. (Ph.D. thesis, University of Bristol, 1987.)

Nye, J.F. 1985. Physical properties of crystals. Oxford, etc., Oxford University Press.

Sverrisson, M., Æ. Jóhannesson, and H. Björnsson. 1980. Radio-echo equipment for depth sounding of temperate glaciers. J. Glaciol., 25(93), 477-486.

Walford, M.E.R. and M.F.L. Harper. 1981. The detailed study of glacier beds using radio-echo techniques. Geophys. J. R. Astron. Soc., 67(3), 487-514.

Watts, R.D. and A.W. England. 1976. Radio-echo sounding of temperate glaciers: ice properties and sounder design criteria. J. Glaciol., 17(75), 39-48. 